\title{
O POLÍTICO DO MEDO E O MEDO DA POLÍTICA
}

\author{
JOSÉ EISENBERG
}

"Medo não, perdi a vontade de ter coragem", dizia Riobaldo. Não é fácil admitir que há tanto ironia quanto verdade nesta frase do personagem de Guimarães Rosa. Estamos habituados a pensar no medo como uma daquelas paixões amarradas ao vício, ou pelo menos à fraqueza de caráter. Ser medroso, afinal, nunca foi uma virtude. Somos escravos dos nossos temores, e perdemos a liberdade quando agimos por medo, não é assim? Riobaldo, no entanto, quando reescreve o sentido do medo, recusa a servilidade desta paixão. Seu medo é perda da vontade de ter coragem. Seu espírito livre se coloca diante de duas escolhas igualmente aceitáveis - ter medo ou ter coragem - e ele escolhe, candidamente, ter medo. ${ }^{1}$

Neste artigo, gostaria de sugerir que na frase aparentemente apenas retórica de Riobaldo, como que justificando ad hoc os seus temores, reside uma compreensão bem mais sofisticada desta paixão misteriosa e de suas conotações profundamente políticas. Ela sintetiza, como mostrarei, uma compreensão sofisticada e surpreendentemente republicana do político que também ocupou diversos pensadores políticos da modernidade, ainda que muitos de seus intérpretes póstumos insistam em demonizá-la. Na política, a coragem de ter medo que está implícita na frase irreverente de Riobaldo é elemento central para a constituição de um sentido verdadeiramente republicano do político. Em particular, ela ajuda a esclarecer importantes aspectos dos atos de legitimar uma autoridade política através do consentimento, de obedecê-la e até mesmo das formas de resistir a ela.

${ }^{1}$ Devo a lembrança desta passagem de Grande Sertão: Veredas a Marilena Chauí, no ensaio "Sobre o Medo", em Novaes, Adauto (org.), Os Sentidos da Paixão, São Paulo: Funarte/Cia. das Letras, 1987. 
Como provocação inicial, acompanhemos a instigante distinção de Carl Schmitt entre o político (a relação amigo-inimigo) e a política (a materialidade inerte das instituições) e partamos da premissa que Hobbes estava certo quando dizia que do medo nasce o político (isto é, a ação política) e do pacto nasce a política, isto é, o imperativo da obediência a um soberano legitimado pelo consentimento. Obviamente, não precisamos levar os passos do raciocínio hobbesiano às suas últimas consequiências, e muito menos ainda justificar o absolutismo que muitos intérpretes costumam atribuir a ele. Mas medo e política imbricam-se de maneiras bastante complexas e, por mais surpreendente que possa soar aos nossos ouvidos ensurdecidos pelas trombetas do liberalismo, de maneiras potencialmente libertadoras.

O que quero mostrar neste pequeno ensaio é que o medo, além de ser uma paixão positiva que move os seres humanos à ação virtuosa que engendra o campo do político, é parte necessária de qualquer projeto emancipatório de uma teoria política moderna. Sem o impulso republicano que o medo organiza na economia dos sentimentos morais, estaríamos, como já estivemos e continuamos a estar em vários sentidos, entregues a uma miríade de formas de dominação. $\mathrm{O}$ medo que impulsiona o ser humano à ação libertadora, entretanto, não é necessariamente o medo hobbesiano da morte violenta, mas sim o medo da servidão, ao mesmo tempo, mãe, filha e irmã do império dos interesses, individuais e coletivos, que o imaginário mercantilista da modernidade impõe sobre nós desde o advento do capitalismo e da doutrina liberal que a ele se acoplou. ${ }^{2}$ Somos escravos, acima de tudo, quando somos escravos das nossas paixões, e só uma delas é capaz de nos catapultar para o reino da ação política e para o império das virtudes: o medo desta servidão.

"A coisa de que mais tenho medo é do medo"3, afirma Montaigne em seu ensaio sobre o medo. É preciso admitir que não é fácil ter coragem de ter medo, e um cético como Montaigne certamente não estava preparado para realizar este salto. Mas é interessante notar que quando Riobaldo diz que perdeu a vontade de ter coragem, ele está irônica e implicitamente afirmando que, ao contrário de Montaigne, não tem medo de ter medo; podemos afirmar, assumindo alguns graus de liberdade na interpretação

2 Discuti mais detalhadamente o império dos interesses na política moderna e como este império acaba por esvaziar o agir virtuoso que define o campo da política em A Democracia depois do Liberalismo (Rio de Janeiro: Relume Dumará, 2003), particularmente nos capítulos 2 e 3 .

${ }^{3}$ Montaigne, Michel de, The Essays, Nova Iorque: The Heritage Press, 1946, p.97 
literária, que Riobaldo sabia, quando fazia aquela afirmação, que homens comuns, como ele, ao perderem o medo de ter medo, mobilizam um outro conjunto de paixões que os habilitam a uma ação política emancipadora.

Em primeiro lugar, aquele que tem coragem de ter medo adquire a esperança de conquistar e superar o medo, o que só pode fazer se, antes de tudo, recusar uma entrega ao voluptuoso movimento de suas paixões, em particular aquelas que orbitam ao redor daquilo que Hobbes denominou do impulso de sobrevivência. Curiosamente, como nos mostra Luiz Eduardo Soares em seu instigante estudo sobre o filósofo inglês, este impulso central da economia das paixões só se manifesta de forma negativa, sob o medo de não ser capaz de saciá-lo, ou de maneira mediada, sob a forma da razão. ${ }^{4}$ Soares tem em mente, evidentemente, a razão prática, voltada à ação, ainda que não especifique isto. Dos movimentos voluntários da paixão, a única modalidade que coincide com a operação da razão prática é o medo. Aquele que teme reflete, e ao invés de atirar-se ao objeto de sua paixão, submete seus desejos a um processo de deliberação que é, ao mesmo tempo, instrumental e pragmático. Instrumental, porque avalia meios para atingir seus fins e julga estes meios sob o critério da eficácia; pragmático, porque avalia o valor do fim almejado sob a luz dos outros fins que compõem sua economia das paixões. O movimento da razão prática, neste sentido, inicia-se no momento em que introduzimos um momento de contemplação e julgamento anterior à ação. O medo, por sua vez, é o titular entre as muitas paixões porque é ele que nos leva a refletir, negativamente, sobre o centro gravitacional da economia das paixões humanas, qual seja, o impulso de sobrevivência. Conclui Luiz Eduardo Soares, em uma chave hegeliana, que "o medo equivale à consciência-de-si de um sujeito movido pela e para a reprodução de si". 5

Da esperança de superação do medo produzida pela razão prática, o ser humano engendra dentro de si o processo de construção de sua coragem. Coragem de resistir àquilo que lhe causa medo, mas também coragem de obedecer àquilo que pode tirar-lhe o medo. Intérpretes de Hobbes que o aproximam do absolutismo, como Leo Strauss, sempre enfatizaram o papel do medo da morte violenta enquanto a mais política das paixões hobbesianas. ${ }^{6}$ Outros, como Renato Janine Ribeiro, nos mostram que a vocação política do ser humano em Hobbes não nasce somente

4 Ver Soares, Luiz Eduardo, A Invenção do Sujeito Universal, Campinas: Editora da Unicamp, 1995.

5 idem, p. 204.

${ }^{6}$ Strauss, Leo, The Political Philosophy of Hobbes, Chicago: University of Chicago Press, 1952. 
do medo, e não se reduz portanto à revelação do imperativo da obediência. O sentimento irmão do medo no pensamento hobbesiano - a esperança também participa da produção daquela vocação, pois se o medo impele o ser humano a pensar no seu futuro e nas formas de evitar o objeto de seu medo, é a esperança que o projeta para o futuro. Sobretudo, é ela que leva o ser humano a crer que o pacto de sujeição que está preste a realizar pode efetivamente eliminar o objeto do medo. Este momento (republicano, talvez?) do pensamento hobbesiano escapou a inúmeros intérpretes do filósofo inglês desde Strauss, ocupados que estavam com o problema da justificação da obediência e não com a sua gênese. Mas não escapou a Renato Janine Ribeiro. ${ }^{7}$

Mas precisamos ressaltar que apesar do impulso de sobrevivência constituir o centro gravitacional da economia das paixões humanas, Hobbes errou ao imaginar que, por causa disto, os seres humanos temem, acima de tudo, a morte violenta. É o próprio Montaigne quem nos lembra que "...o medo é mais inoportuno e mais insuportável que a morte". 8 Afinal, se fôssemos avisados, por exemplo, de que seríamos sujeitos a inevitáveis torturas brutais a partir de amanhã, não escolheriam muitos de nós, em inúmeras circunstâncias, a morte súbita ainda que violenta? Entre a morte violenta agora ou o medo permanente de que a dor nos acometa amanhã, é razoável supor que um hobbesiano poderia muito bem escolher a morte. $\mathrm{O}$ medo que move o ser humano negativamente do impulso de sobrevivência à razão prática, portanto, não é o medo da morte violenta mas sim o medo das dores que acompanham a servidão.

Quando o ser humano que teme, através da razão prática, descobre que há esperança de suprimir o medo, ele adquire coragem. Esta coragem, vale ressaltar, é antes de qualquer coisa, uma coragem de ter medo, isto é, uma coragem de cessar os atos intempestivos a que nos levam as paixões para refletir primeiro, depois agir. Nesta contemplação antecipatória, o ser humano estrategiza sua ação e descobre outra paixão emancipadora: sua sociabilidade reflexiva. Diferente da sociabilidade natural preconizada pelo aristotelismo - um dado antropológico inquestionável, resultado de uma interpretação comparativo-etnográfica do ser humano, mas de pouca

\footnotetext{
7 Ver Ribeiro, Renato Janine, A Marca do Leviatã, São Paulo: Ed. Ática, 1978 e Ao Leitor sem Medo: Hobbes escrevendo contra o seu tempo, $2^{\mathrm{a}}$ ed., Belo Horizonte: Ed. UFMG, 1999. Para uma excelente revisão dos debates sobre a obediência em Hobbes no século XX, ver Pogrebinschi, Thamy, O Problema da Obediência em Thomas Hobbes, São Paulo: EDUSC, 2003.

8 Montaigne, op.cit., p. 98.
} 
relevância para uma teoria política - , a sociabilidade reflexiva é algo que o ser humano inventa e reinventa quando ele descobre os limites de um ceticismo estoicista e a impossibilidade de superar o medo da servidão sem coordenar, comunicativa e racionalmente, com outros seres humanos, uma solução para os seus temores. Entregue às desigualdades sociais engendradas pela sociabilidade natural - de que falava muito bem Rousseau e que nos leva, na melhor das hipóteses, a uma sociedade civil definida por relações de servidão (senhor/escravo, rico/pobre, forte/fraco) - os seres humanos dominados e que têm coragem de ter medo recusam-se a ficar entregues às intempéries da Fortuna. Estes engajam em um processo de coordenação que permita que eles superem sua condição servil coletivamente e construam, no mote de enorme força emancipatória proferido por Marx, uma sociedade justa onde "de cada um de acordo com suas capacidades, a cada um de acordo com suas necessidades".

Assim, desta coordenação nasce um pacto em que, antes de mais nada, todos têm uns para com os outros obrigações e deveres que, ao contrário do que pensavam Locke e tantos outros contratualistas liberais depois dele, não nascem de um acordo mercantil que beneficia mutuamente a todos, mas sim de um pacto de superação coletiva e coordenada do medo. Hobbes sabia muito bem desta diferença entre pactos e contratos. Basta ler com atenção o capítulo XIV do Leviatã. Na ação coletiva gerada por esta sociabilidade reflexiva, as obrigações e os deveres não nascem nem se reproduzem na reciprocidade dos interesses individuais, mas sim na convergência racional dos agentes determinados a ter coragem de ter medo e esperançosos de superá-lo. Seja no batalhão de soldados do front das tantas guerras da era moderna, seja nos novos movimentos sociais organizados da segunda metade do século XX, a lógica da ação coletiva gerada por esta sociabilidade reflexiva não guarda nenhuma semelhança com o modelo olsoniano tão hegemônico nas ciências sociais contemporâneas. Desta lógica nasce um modelo da política no qual, por mais paradoxal que possa parecer, não há lugar para os interesses de indivíduos ou de grupos, porque quando se sente medo estes interesses são sempre, desde o primeiro instante, deslocados para a periferia da economia das paixões humanas. Soldados defendem a pátria, manifestantes defendem a suas causas, e os laços de solidariedade entre eles raramente dependem de ganhos recíprocos. A lógica de sua ação coletiva está sempre impregnada de uma coragem de dizer (gritar?) para o mundo e para os seus inimigos: "tenho medo de não fazer nada e tenho a esperança de superar este medo se agir coordenadamente". 
Da perspectiva da construção desta sociabilidade reflexiva, é interessante notar que não há fim secular para o qual a sobrevivência possa ser concebida como um meio. Temos somente um impulso de sobreviver que define a nossa condição humana e todas as paixões que a acompanham. Quando este impulso se manifesta negativamente na forma do medo, não escolhemos fazer alguma coisa a respeito; precisamos, somos impelidos, a fazer algo. E desta obrigação para consigo mesmo emerge uma disposição ao dever do qual nasce a virtude cívica quando coordenamos nossas ações para superar o medo. Ainda que os contratualistas tenham se equivocado diversas vezes ao projetar nesta coordenação uma transação mercantil e "interessada" entre indivíduos autônomos, eles certamente (e entre eles Hobbes, acima de tudo), entenderam algo crucial à interpretação da política: ela nasce desta sociabilidade reflexiva.

Dentre os deveres que emergem da política, o mais importante deles é o da obediência. Na interpretação do aristotelismo que define uma parte importante da tradição do pensamento político moderno, obedecer é um dever pelo simples fato da autoridade política ser uma instituição natural, assim com a autoridade paternal. A força emancipatória da tradição que se opôs ao aristotelismo na modernidade reside precisamente em ter se contraposta a esta tese naturalista. Para ela, a obediência se diferencia da servidão por um motivo aparentemente sutil, mas central à sua lógica argumentativa: a obediência é voluntária, ou seja, consentida. A servidão voluntária que perturbou La Boethie no contexto de uma reflexão sobre a tirania não pode ser reduzida a este contexto. Em outros contextos, obedecer porque tenho medo não é servir voluntariamente, mas somente reconhecer que a constituição deste artífice chamado autoridade política tranqüiliza a alma, protege o corpo e nos insere em uma comunidade ordenada cujas regras podem ser igualmente válidas para todos. Em outras palavras, o medo gera consentimento.

Mas o que é este consentimento gerado pelo medo? Ou melhor, como determinar quando a obediência é devida porque ela foi consentida? A resposta que nos é ofertada pelo anti-aristotelismo do pensamento contratualista é um tanto vaga e indeterminada. Dizem-nos que devemos consentir a uma autoridade política quando ela é legítima, e ela é legítima se for consentida. Mas então continuamos com a mesma questão: como determinar quando a legitimidade da autoridade política foi gerada pelo consentimento?

Sugiro como ponto de partida para uma busca de respostas a esta indagação um pequeno evento da história colonial brasileira que é, no 
entanto, representativo dos dilemas colocados pela questão. Em 1553, os jesuítas Manuel da Nóbrega e José de Anchieta, engajados que estavam no empreendimento de converter os índios do Brasil ao cristianismo, decidiram fazer uma experiência em São Vicente. Naquele ano, os dois jesuítas decidiram trazer três tribos localizadas a aproximadamente 70 quilômetros da costa, para morar em um único lugar conhecido como Piratinim, ou Piratininga, um vilarejo que mais tarde se tornaria a cidade de São Paulo. Ao invés de viajarem para as tribos dos nativos para convertêlos, como faziam anteriormente, agora eram os índios que se locomoveriam para Piratininga, onde os missionários empreenderiam seus esforços catequizadores:

E do mar dez legoas pouquo mais ou menos, duas legoas de huma povoação de João Ramalho, que se chama Piratinim, onde Martin Afonso de Sousa primeiro povoou, ajuntamos todos os que Nosso Senhor quer trazer à sua Igreja e aquelles que sua palavra e evangelho engendra polla pregação. E estes de todo deixão seus custumes e se vão estremando dos outros, e muita esperança temos de serem verdadeiros filhos da Igreja; $(. . .)^{9}$

AAldeia de Piratininga era uma comunidade formada por índios ainda não convertidos, mas dispostos a viver sob a proteção dos irmãos da Companhia de Jesus, vivendo de uma agricultura de subsistência e permitindo que suas crianças fossem educadas pelos jesuítas segundo a moral e os costumes da religião cristã. Embora o sucesso do projeto da Aldeia de Piratininga tenha renovado o fervor missionário de Nóbrega, os índios somente tinham consentido em se mudar para a nova localidade porque confiavam em Anchieta, que tinha conseguido converter muitos índios através da cura, isto é, dos seus parcos conhecimentos das causas e soluções para as inúmeras doenças que os colonos transmitiam aos nativos. Nóbrega sabia que as habilidades médicas do companheiro eram difíceis de reproduzir, pois uma coisa era se tornar autoridade religiosa porque capaz de curar corpos, outra coisa muito diferente era transferir esta autoridade médicocarismática a outros irmãos da ordem. Ou seja, não bastava reunir os índios em um só local para adquirir a autoridade necessária para convertê-los; era preciso curá-los de suas doenças, coisa que poucos jesuítas sabiam fazer.

9 P. Manuel da Nóbrega, carta a d. João III, outubro de 1553 in Monumenta Brasiliae, org. Serafim Leite, vol. III, p. 16. 
Três anos depois da experiência com Anchieta em São Vicente, Nóbrega concebeu uma reforma do empreendimento missionário para toda a costa brasileira, adotando o princípio de reunir os índios em um só local como havia logrado em Piratininga. Mas, como não podia contar com os dotes médicos de seus pares para convencer os índios, Nóbrega introduziu na reforma uma nova maneira de persuadir os nativos a saírem de suas tribos para morar em uma aldeia. Assim como em Piratininga, os índios seriam "convidados" a se mudarem para os novos povoamentos. Mas os jesuítas levariam consigo uma tropa do governo colonial e, caso os nativos recusassem o convite, estariam sujeitos a uma "guerra justa" movida pela tropa. De acordo com Nóbrega, dessa maneira os índios não eram forçados a aceitar a fé cristã, já que a bula papal Sublimus Dei de 1537 proibia o uso da força na conversão dos povos do Novo Mundo. Pelo contrário, os índios estariam consentindo em se submeter à autoridade dos padres pelo medo de serem mortos ou escravizados em consequiência da guerra justa movida pelas armas do exército colonial português. O conceito central da reforma projetada por Nóbrega era o medo. Os índios aceitariam a autoridade política do jesuíta e viveriam sob a sua "polícia cristã" (expressão que curiosamente designava os costumes e hábitos dos cristãos europeus do século XVI) por medo de resistir ao "convite". Para Nóbrega, esta estratégia não era o mesmo que coagi-los a adotar a fé cristã; forçados seriam a viver vestidos, em monogamia, sem canibalizar seus inimigos de guerra etc. Mas para a fé, os índios seriam convertidos pela persuasão, com calma, tolerância e adaptando o cristianismo aos costumes menos ofensivos dos nativos.

Nóbrega já havia notado a força do medo para a conversão do gentio logo que chegou ao Brasil. Na primeira carta edificante que escreveu, o jesuíta conta que os índios não têm deuses nem ídolos. Não existiam correspondentes no vocabulário tupi para a palavra Deus, nem tampouco para qualquer palavra do português semanticamente correlata. Ele então chegou à conclusão de que a palavra tupi para "trovão" - Tupã ou Tupana - era a mais apropriada para traduzir "Deus". Os índios entendiam o sentimento de medo e temiam o trovão sobre todas as coisas:

Esta gentilidad a ninguna cosa adora, ni conocen a Dios solamente a los truenos llaman Tupana, que es como quien dize cosa divina. $\mathrm{Y}$ assí nós no tenemos otro vocablo más conveniente para los traer conoscimiento de Dios, que llamrle Padre Tupana. ${ }^{10}$ 
Vindos ao Brasil com o pretexto de demonstrar o infinito amor de seu Deus pelos pagãos, Nóbrega e seus colegas acabaram por ensinar aos índios o que eles deviam temer. Esta imagem de um Deus amedrontador não era estranha à doutrina cristã, encontrando freqüentes manifestações no Velho Testamento, mas a mudança de uma imagem de um Deus caridoso, pleno de amor por todos os seres humanos, para a de um Deus temível exprimia uma série de contradições existentes entre o intento original do empreendimento jesuítico no Brasil e suas práticas reais para com os Tupi depois da reforma do empreendimento missionário. A mais importante dessas contradições se dava entre o uso da autoridade secular para infligir medo aos pagãos e a teologia jesuíta do amor que prescrevia a conversão através da persuasão. Não seria a reforma proposta por Nóbrega uma maneira mal disfarçada de forçar os índios à conversão? Amedrontar não seria o mesmo que coagir? Segundo a interpretação de Nóbrega, os índios submetidos dessa maneira ao mando jesuítico estavam, de fato, consentindo em fazê-lo. Para ele, provocar o medo não era uma forma de coerção mas sim uma forma de persuasão, e ao fazer tal argumento, ele encontrava-se na boa companhia de São Tomás de Aquino.

Segundo os ensinamentos de São Tomás, o medo não é a mesma coisa que a coerção. De acordo com Aquino, o objeto do medo é o mal. Mas o mal, segundo São Tomás, pode vir de Deus:

O objeto primeiro e formal da fé é um bem, a verdade primeira. Mas entre as coisas materiais da fé, também propõe crer em certos males; é um mal, por exemplo, não se submeter a Deus ou apartar-se Dele, e os pecadores sofrerão males punitivos de Deus. Neste sentido, a fé é causa do medo. ${ }^{11}$

Em outras palavras, Deus fez com que os seres humanos temessem a falta de fé e a punição de seus pecados. Deus criou o medo, que é um mal, por uma boa causa. São Tomás conclui que "Deus é a causa de todo medo". 12

Para o Doutor Angélico, havia dois tipos de medo: o medo servil, que é o temor da punição desencadeada pela ira divina, e o medo filial, o temor inspirado pela sujeição à autoridade divina. Enquanto o

11 Aquino, São Tomás de, Suma Teológica, tomo VII, 2-2, q.7, a.1, Madrid: La Editorial Católica, 1959, p. 292.

12 Idemorque: The Heritage Press, 1946, p. 97 
primeiro tipo de medo pode ser experimentado por todos, sejam fiéis ou infiéis, o segundo é próprio daqueles que acreditam em Deus. Falta de fé, diz Aquino, é a causa do medo servil, enquanto que a fé propriamente dita produz o medo filial. Se o medo filial é conseqüência de uma fé já formada, então ele logicamente não pode causar a conversão. Mas aquele que ignora a fé pode aprender a temer a Deus através do medo servil.

A noção de Nóbrega de que os índios aceitariam a fé através do medo estava em perfeita concordância, portanto, com a interpretação tomista do medo, a qual tem a distinção entre medo filial e medo servil em seu centro. Ao discutir o conceito de medo, Nóbrega e seus colegas jesuítas no Brasil estavam de fato empregando a noção tomista de medo servil que, enquanto causa possível da fé, proporcionou uma justificação teológica para a reforma das missões jesuíticas no Brasil. O medo provocado pela ameaça da autoridade secular era análogo ao medo da punição divina.

Voltemos então à pergunta inicial deste ensaio: o consentimento gerado pelo medo produz uma autoridade legítima a quem devemos obediência? Se retornarmos às reflexões sobre o medo que fizemos agora há pouco, veremos que a conclusão a que chegamos é surpreendentemente e, talvez para alguns, desoladora: sim, este consentimento é legítimo. Como Riobaldo, devemos dizer que os índios que, por medo das armas do governo colonial, se submeteram à autoridade dos jesuítas "perderam a vontade de ter coragem." Não quero com isto dizer que a autoridade legitimada pelo consentimento gerado pelo medo é sempre justa. Questões de justiça sempre implicam na aplicação de critérios morais e éticos externos através dos quais nos perguntamos se determinado arranjo social gera o bem ou o mal para um determinado indivíduo ou comunidade. Em outras palavras, nem tudo que é justo é legítimo e nem tudo que é legítimo é necessariamente justo. Mas temos que admitir, como nos ensina Maquiavel, que o príncipe que estabelece sua autoridade por conquista, uma vez aceito pelos conquistados, é tão legítimo quanto aquele que é aclamado pelos cidadãos. A distinção central consiste no fato de que a legitimidade da autoridade política reside no consentimento e não nas razões que se tem para consentir.

Somente desta maneira podemos dar sentido pleno a um elemento central do pensamento político republicano, que é o direito à resistência. Este direito não existe somente quando a autoridade política não é legítima, mas sempre que se considerar que ela agiu de maneira injusta. Caso contrário, a resistência seria um direito somente contra a tirania, e bem sabemos que existem inúmeras encruzilhadas políticas bastante distintas do horizonte da tirania que ainda produzem um direito à resistência. 
Se fôssemos reconstruir a história do genocídio indígena nas Américas do ponto de vista dos índios, teríamos que dizer que eles tinham não só o direito mas o dever da resistência, e aqueles que consentiram a autoridade dos jesuítas por medo, haviam perdido a coragem de ter medo, perderam a esperança de superá-lo e escolheram, por conseguinte, abdicar de sua soberania política. É razoável supor, ainda que evidência disto seja impossível de coletar, que tribos que não capitularam à estratégia dos jesuítas viam com olhos reprobatórios a decisão das tribos que sucumbiam à autoridade dos padres.

Entender esse ponto é fundamental para que compreendamos que a guerra dos fracos contra os fortes é sempre mais virtuosa do que a submissão. Afinal, o que seria das lutas contra a escravidão sem as narrativas de resistência que pontuam a sua história? É Montaigne mais uma vez quem nos ensina em um de seus ensaios que "Aqueles que temem perder suas propriedades, de serem exilados ou escravizados, vivem em angústia constante, incapazes de comer, beber ou dormir, enquanto que os pobres, os exilados e os escravos, freqüentemente vivem felizes como qualquer um." O preço da liberdade, muitas vezes, é a felicidade. Aqueles que conseguem transformar seus medos em coragem e esperança não terão a felicidade do pobre, do exilado ou do escravo de que ironicamente fala Montaigne. Mas manterão, em compensação, sua soberania política. A coragem de ter medo e, através do uso da razão, produzir a esperança de superá-lo, tem a potência de produzir uma ação política soberana, pois, afinal, aquele que tem coragem de ter medo, ainda não perdeu a vontade de ter coragem. Como nos ensina Montaigne em uma passagem que, de certa forma, contradiz a sua máxima de que "a coisa de que mais tenho medo é do medo", "o medo mostra sua força suprema quando ele nos devolve a coragem que havia antes roubado de nosso dever e de nossa honra."

O medo de ter medo, por outro lado, gera a angústia, passiva e paralisante. É ela que domina o terror dos regimes totalitários de que falava Hannah Arendt. Sob o totalitarismo, o medo que se sente é de um todo que se esvaece nas capilaridades de uma vida social sufocada pela opressão, em que já não é mais possível localizar o objeto daquela paixão. $O$ terror pode vir de qualquer lugar, a qualquer hora, e portanto retira do sujeito a capacidade de ter coragem de ter medo. Ele não pode confiar em ninguém para coordenar uma sociabilidade reflexiva que gere esperança coletiva de superação. O inimigo mora ao lado, em todo lugar, e ao mesmo tempo. Sob o totalitarismo, a philia aristotélica dá lugar à angústia: ao medo de ter medo. Na tirania, por outro lado, o objeto do medo é claro: a autoridade 
política arbitrária. Ainda que consentida, por que tenho medo dela, a tirania me permite ter coragem de ter este medo, e de ter esperança, portanto, de superá-lo. Sob o totalitarismo, o político desaparece. Sob a tirania, ele está apenas adormecido, desaparecendo somente a política.

O medo é, portanto, uma paixão positiva e emancipadora, criadora do político e da política em sua acepção republicana. $\mathrm{O}$ inimigo do político não é o medo, não é a obediência, e nem mesmo a autoridade política. O inimigo da ação política é o medo de ter medo. Enquanto que do medo nasce a razão prática e a esperança de emancipar-se das causas do medo, gerando assim uma sociabilidade reflexiva que podemos chamar de ação política, do medo de ter medo nasce a angústia que gera uma apatia em relação ao político que interessa somente àqueles que dela usurpam. Enquanto que da coragem de ter medo pode nascer uma república, na qual temos o dever de obedecer às regras legítimas, o direito de cobrar de todos que cumpram seus deveres, o direito de resistir quando a regra é injusta, e o dever de resisti-la quando ela nos é imposta, do medo de ter medo nasce a apatia que arremessa os sujeitos sociais em um jogo instrumental de articulação dos interesses privados, individuais ou coletivos, colonizando a esfera pública e fazendo desaparecer, gradualmente, o político das sociedades contemporâneas. Não procede, portanto, ao meu ver, a leitura espinoziana do medo que Marilena Chauí nos oferece no artigo citado no começo deste ensaio. Afinal, o problema central não é a dicotomia entre medo e coragem, mas sim, a dicotomia entre o medo de ter medo e a coragem de ter medo. E isto se explica pelo simples fato de que não podemos excluir o medo da economia das paixões humanas na busca de cidadãos virtuosos moldados à imagem dos heróis dos épicos da Grécia Antiga. Devemos aceitar o caráter estritamente ontológico do medo enquanto constituinte da experiência humana. $\mathrm{O}$ medo constrói o inimigo e define os amigos, constituindo assim o político. E se tivermos coragem de ter medo é possível vislumbrar uma política republicana em que a materialidade inerte das instituições dê lugar a uma vida cívica que energiza e revitaliza cotidianamente a operação da política.

JOSÉ EISENBERG é professor de Ciência Política do Instituto Universitário de Pesquisas do Rio de Janeiro (Iuperj). 


\section{RESUMOS/ABSTRACTS}

\section{O POLÍTICO DO MEDO E O MEDO DA POLÍTICA}

JOSÉ EISENBERG

Este artigo examina o papel do medo na legitimação da autoridade política. Seu argumento é que o medo é um sentimento moral importante na constituição de um soberano legítimo, e para tanto mobiliza exemplos da teoria política e das práticas políticas do século XVI para ilustrá-lo.

Palavras-chave: Teoria Política Moderna; Medo; Autoridade; Soberania.

\section{THE POLITICIAN OF FEAR AND THE FEAR OF POLITICS}

This article analyzes the role of fear in the legitimation of political authority. It argues that fear is an important moral sentiment in the constitution of a legitimate sovereign, and utilizes examples from political theory and political practices of the sixteenth century to illustrate this argument.

Keywords: Modern Political Theory; Fear; Authority; Sovereignty. 